\title{
Local giant cell foreign body reaction after silicone injection for fecal incontinence in humans: two case reports
}

\author{
B. van Wunnik $\cdot$ A. Driessen $\cdot$ C. Baeten
}

Received: 8 February 2011/ Accepted: 3 June 2011/Published online: 22 June 2011

(c) The Author(s) 2011. This article is published with open access at Springerlink.com

\begin{abstract}
Since the 1990s, one of the methods used for treating fecal incontinence due to internal anal sphincter defects has been the injection of bulking agents. The aim of this paper is to report two cases of local giant cell foreign body reaction after injection of $\mathrm{PTQ}^{\mathrm{TM}}$ in humans. To the best of the authors' knowledge, this is the first report of an adverse immune response to silicone injection in humans.
\end{abstract}

Keywords PTQ - Fecal incontinence $\cdot$ Injectable bulking agents $\cdot$ Silicone

\section{Introduction}

Fecal incontinence is a socially disabling condition with an adverse affect on quality of life, for which several surgical treatments are available. The etiology is often multifactorial, and loss of stool or fecal soiling may be the result of one or more alterations of the mechanisms that normally assure continence. The internal anal sphincter (IAS) and the vascular cushions in the anal canal make the largest contribution to anal resting pressure. Damage to the IAS may not always cause complete incontinence but may result in passive fecal incontinence due to a poor anal seal. This may be visualized by endosonography as an anatomical irregularity of the anal canal, known as a keyhole defect, or a decrease in thickness. Anorectal manometry values are

B. van Wunnik $(\varangle) \cdot$ C. Baeten

Department of Surgery, Maastricht University Medical Centre,

P. Debyelaan 25, 6202 AZ Maastricht, The Netherlands

e-mail: b.van.wunnik@mumc.nl

A. Driessen

Department of Pathology, Maastricht University Medical Centre,

P. Debyelaan 25, 6202 AZ Maastricht, The Netherlands usually within the normal range. Injectable bulking agents have become a treatment option with the introduction of minimally invasive procedures. In 1993, injection of polytetrafluoroethylene was introduced by Shafik [1]. Since then, autologous fat, glutaraldehyde cross-linked collagen, pyrolytic carbon-coated beads, synthetic calcium hydroxylapatite ceramic microspheres, Teflon and a silicone biomaterial (PTQ ${ }^{\mathrm{TM}}$, Uroplasty BV, Geleen, The Netherlands) have been injected. Injecting a bulking agent around the IAS or into the keyhole defect provides an increased pressure improving the seal and restoring the symmetry of the anal canal. Reported problems with the use of bulking agents are deterioration over time and migration, absorption, and deformation of implants.

Our center uses PTQ ${ }^{\mathrm{TM}}$ implants. This product is a heterogeneous injectable material consisting of polydimethylsiloxane particles suspended in a bioexcretable carrier hydrogel of polyvinylpyrrolidone (Povidone, PVP). Over 99 volumetric percentages of the particles are larger than $80 \mu \mathrm{m}$. This size is most likely larger than the maximum size of particles ingested by macrophages. Giant cells are able to amass much cytoplasm, but should have difficulty engulfing these particles. Furthermore, it is unlikely that these large particles could gain direct access to lymphatic and small vessels [2]. An inflammatory reaction to the implant material has been reported in rats by Nijhuis [3] and in dogs by Smith [4]. We report two cases of local giant cell foreign body reaction after injection of $\mathrm{PTQ}^{\mathrm{TM}}$ in humans.

\section{Case 1}

A 55-year-old male with fecal soiling and incontinence for flatus was treated twice with $\mathrm{PTQ}^{\mathrm{TM}}$ in 2005 and 2006. This patient had had several surgical interventions for anal 
fissures and soiling in other centers. Anal fissures were treated with Lord's procedure and lateral sphincterotomy, and an anal repair was performed to restore the sphinctercomplex. A rectal prolapse was corrected by rectopexy. Preoperative investigations were performed. A bowel habit diary showed incidental loss of stool and daily soiling. Anorectal manometry revealed a low resting pressure of $44 \mathrm{mmHg}$, but otherwise normal values. Defecography showed incontinence, without other abnormalities. Pudendal nerve terminal motor latency (PNTML) revealed normal latency values. Endosonography showed scarring of the IAS from 1 to 6 o'clock and a defect in the external anal sphincter (EAS) from 9 to 11 o'clock. Injection of $\mathrm{PTQ}^{\mathrm{TM}}$ in this defect did initially improve continence, but 6 months later, the patient was put on the waiting list for an artificial bowel sphincter (ABS) due to leakage of stool. In early 2008, patient visited our institution with severe complaints of pain in the anal region. A MRI scan showed multiple abscesses in the perineal area, a subsphincteric connection with the anus, and a large defect in the IAS and EAS from 9 to 3 o'clock. Resection of these lesions revealed a total of six cyst-like tumors positioned in a chain. The defect was closed, and 2 months later, the ABS was implanted.

The pathology department received three tissue fragments of varying sizes. The largest piece had a size of $2.5 \times 1.5 \mathrm{~cm}$. These specimens were solid in consistency. Microscopic examination showed a hypercellular inflammatory infiltrate, partially surrounded by fibrous connective tissue. This inflammatory infiltrate was heterogeneous in composition, consisting mainly of giant cells (Fig. 1). These giant cells were multinucleated cells, containing foreign material in their cytoplasm. This foreign material, which had an oily appearance, did not polarize. Besides giant cells, foamy macrophages and some lymphocytes were seen.

\section{Case 2}

A 58-year-old male with a 33-year history of pain in the anal region after abscess and fistula surgery was treated with $\mathrm{PTQ}^{\mathrm{TM}}$ in 2007 for soiling. Preoperative investigations were performed. A bowel habit diary showed no loss of stool and daily soiling. Defecography showed no abnormalities. Pudendal nerve terminal latency revealed normal latency values. Anorectal manometry was normal, resting pressure was $91 \mathrm{mmHg}$, and squeeze pressure was $214 \mathrm{mmHg}$. Endosonography showed excessive scarring of the IAS and a keyhole defect dorsally. Injection of PTQ ${ }^{\mathrm{TM}}$ in the defect did not improve continence, and patient was started on retrograde colonic irrigation to treat soiling and occasional loss of stool. Persisting pain led to an MRI scan, which demonstrated a dorsal defect in the anal canal

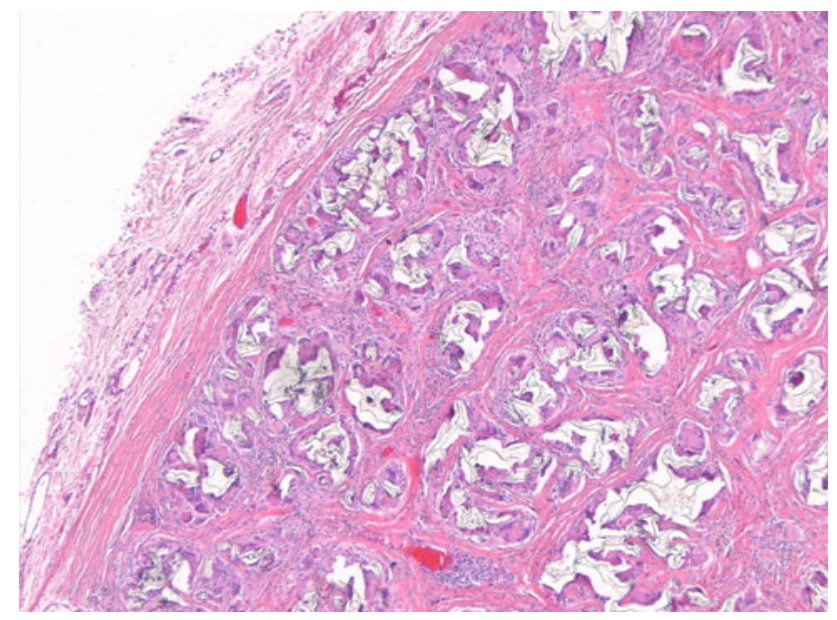

Fig. 1 This photograph shows a foreign body reaction with presence of numerous giant cells $(\mathrm{H} / \mathrm{E}, 50 \mathrm{x})$

between 3 and 6 o'clock with a central fluid collection. This collection had a connection with a second intersphincteric fluid collection. A third and fourth conjoined collection were seen behind the musculus puborectalis. When the fluid was removed, a total of four cyst-like tumors positioned in a chain were revealed. The anal pain remained and continence was maintained with irrigation. The pathology department received 4 irregular tissue fragments with a maximal size of $3 \mathrm{~cm}$. These specimens consisted of fibrous tissue without any anal or rectal mucosa. Microscopic examination revealed a similar picture as in the previous patient: samples showed a foreign body reaction with presence of numerous giant cells, surrounding similar foreign material (Fig. 2).

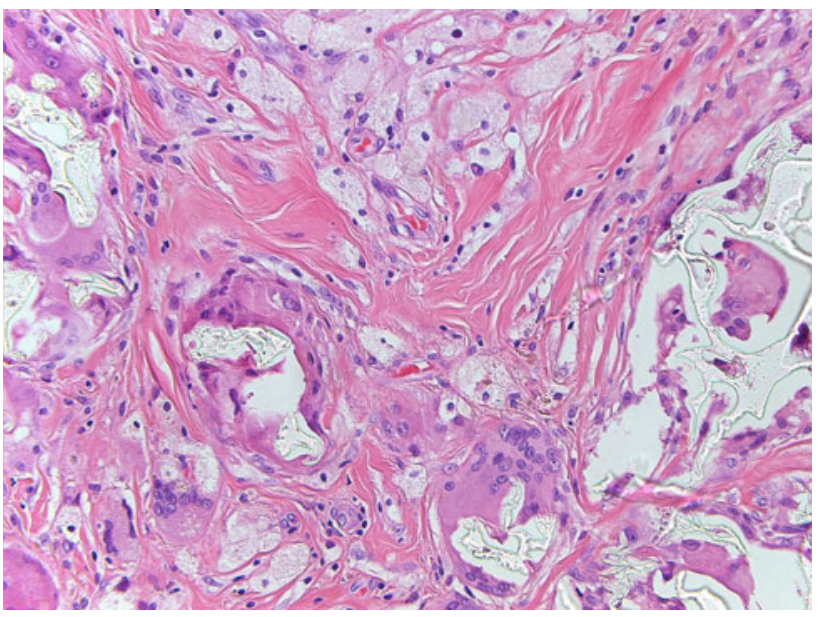

Fig. 2 Large magnification reveals the presence of giant cells and foamy macrophages. The giant cells contain foreign material, which has an oily appearance $(\mathrm{H} / \mathrm{E}, 200 \mathrm{x})$ 


\section{Discussion}

Since the introduction of bulking agents to improve continence in patients with an IAS defect, results have been mixed and a functional deterioration after 2 years has been reported [5]. In a systematic review, Luo et al. concluded that there is currently little evidence for the effectiveness of injectable bulking agents in managing passive flatus incontinence [6]. Furthermore, they concluded that the identified injectable bulking agents appeared to be safe with only minor complications reported. Migration of bulking agent was described in 14 out of 420 patients $(3 \%$, 12 out of 208 with $\mathrm{PTQ}^{\mathrm{TM}}$ ). No foreign body reaction was reported. Similar conclusions were drawn by Maeda et al. in a Cochrane review [7]. Reviews published in the field of urology do not report any foreign body reaction to silicone implants [8, 9]. In vivo studies in animals have shown quiescent to marked foreign body inflammatory reactions as part of encapsulating the product in the first few weeks after injection [3, 4, 10].

Our center has performed approximately $50 \mathrm{PTQ}^{\mathrm{TM}}$ procedures, and literature describes approximately 260 patients. We feel this number of patients is too small to serve as a basis for speculation about the incidence of this rare medium-term adverse immune response.

This is, to the best of our knowledge, the first report on an adverse immune response to silicone injection for fecal incontinence in humans. Surgeons considering the use of $\mathrm{PTQ}^{\mathrm{TM}}$ need to be aware of the possibility of an adverse immune response to this product.

Open Access This article is distributed under the terms of the Creative Commons Attribution Noncommercial License which permits any noncommercial use, distribution, and reproduction in any medium, provided the original author(s) and source are credited.

\section{References}

1. Shafik A (1993) Polytetrafluoroethylene injection for the treatment of partial fecal incontinence. Int Surg 78:159-161

2. Solomon LZ, Birch BR, Cooper AJ, Davies CL, Holmes SA (2000) Nonhomologous bioinjectable materials in urology: 'size matters'? BJU Int 85:641-645

3. Nijhuis PH, van den Bogaard TE, Daemen MJ, Baeten CG (1998) Perianal injection of polydimethylsiloxane (Bioplastique implants) paste in the treatment of soiling: pilot study in rats to determine migratory tendency and locoregional reaction. Dis Colon Rectum 41:624-629

4. Smith DP, Kaplan WE, Oyasu R (1994) Evaluation of polydimethylsiloxane as an alternative in the endoscopic treatment of vesicoureteral reflux. J Urol 152:1221-1224

5. de la Portilla F, Vega J, Rada R et al (2009) Evaluation by threedimensional anal endosonography of injectable silicone biomaterial (PTQ) implants to treat fecal incontinence: long-term localization and relation with the deterioration of the continence. Techn Coloproct 13:195-199

6. Luo C, Samaranayake CB, Plank LD, Bissett IP (2010) Systematic review on the efficacy and safety of injectable bulking agents for passive faecal incontinence. Colorectal Dis 12:296-303

7. Maeda Y, Laurberg S, Norton C (2010) Perianal injectable bulking agents as treatment for faecal incontinence in adults. Cochrane Database Syst Rev CD007959

8. ter Meulen PH, Berghmans LC, van Kerrebroeck PE (2003) Systematic review: efficacy of silicone microimplants (Macroplastique) therapy for stress urinary incontinence in adult women. Eur Urol 44:573-582

9. Lightner DJ (2002) Review of the available urethral bulking agents. Curr Opin Urol 12:333-338

10. Radley SC, Chapple CR, Lee JA (2000) Transurethral implantation of silicone polymer for stress incontinence: evaluation of a porcine model and mechanism of action in vivo. BJU Int 85:646-650 